\title{
IMPLEMENTAÇÃO DE SISTEMAS AUTÔNOMOS DE GERAÇÃO DE ENERGIA PARA A \\ REGIÃO DO SEMIÁRIDO PARAIBANO
}

\author{
IMPLEMENTATION OF AUTONOMOUS ENERGY GENERATION SYSTEMS FOR THE REGION OF \\ THE PARABAN SEMIARID
}

VANESSA ROSALES BEZERRA, M.SC. |UEPB

CARLOS ANTÔNIO PEREIRA DE LIMA, Dr. | UEPB

VALDERI DUARTE LEITE, Dr. | UEPB

LUIS REYES ROSALES MONTERO, Dr. | UFCG

KEILA MACHADO DE MEDEIROS, Dra.|UFRB

\begin{abstract}
RESUMO
A busca por novos recursos energéticos possuindo baixos índices de emissão de poluentes faz com que a sociedade científica se volte para a pesquisa em energias renováveis para um desenvolvimento sustentável. O hidrogênio surge neste cenário socioambiental como um promissor vetor energético autossustentável para substituir os combustíveis fósseis. A produção de hidrogênio através da eletrólise da água vem sendo bastante explorada devido à geração de densidade de corrente elétrica maior quando comparada a outros métodos. As pesquisas relacionadas a produção deste gás estão sendo concentradas com a geração de energia elétrica. Diante da crise energética em que vivemos, as células combustíveis inserem-se como uma alternativa para produção de energia elétrica. $O$ interesse neste sistema reside na eficiência do mesmo gerar energia utilizando uma fonte renovável como combustível. A partir desta nova perspectiva exposta, o presente trabalho tem como objetivo evidenciar o princípio de funcionamento de um reator eletrolítico, painel solar e uma célula combustível em residências como proposta a ser utilizado no semiárido da Paraíba.
\end{abstract}

PALAVRAS CHAVE: Energia Solar; Energia Fotovoltaica; Hidrogênio; Energia Elétrica; Célula de Combustível;

\begin{abstract}
The search for new energy resources with low levels of pollutant emissions makes the scientific society turn to renewable energy research for sustainable development. Hydrogen emerges in this socio-environmental scenario as a promising self-sustaining energy vector to replace fossil fuels. Hydrogen production through water electrolysis has been widely explored due to the generation of higher electric current density when compared to other methods. Research related to the production of this gas is being concentrated with the generation of electricity. Given the energy crisis in which we live, fuel cells are inserted as an alternative for the production of electricity. The interest in this system lies in its efficiency to generate energy using a renewable source as fuel. From this new perspective exposed, the present work aims to highlight the principle of operation of an electrolytic reactor, solar panel and a fuel cell in homes as proposed to be used in Paraíba semiarid.
\end{abstract}

KEY WORDS: Solar Energy; Photovoltaics; Hydrogen; electricity; Fuel cell; 


\section{INTRODUÇÃO}

Estima-se que reservas de petróleo conhecidas durem em torno de 50 anos. Com a redução dessas reservas os preços em um futuro próximo atingirão valores impraticáveis para aplicação como combustível. Diante deste cenário, o potencial de uso do hidrogênio como fonte intermediária vem ganhando notoriedade mundial. $\mathrm{O}$ armazenamento e uso deste componente oferece possibilidades para gerenciamento de energia do futuro. $\mathrm{O}$ hidrogênio pode ser gerado por fontes renováveis, energia nuclear e por combustíveis fósseis com captura de carbono (KNOB, 2013).

O hidrogênio não é um combustível primário, encontra-se quase sempre associado a outros elementos químicos e para utilizá-lo é necessário extraí-lo da sua fonte de origem. A partir de processos adequados é possível recuperar toda energia química, térmica e elétrica vinculada a molécula de hidrogênio produzido.

Este vetor energético pode ser extraído de combustíveis fósseis, como o gás natural e carvão. A tecnologia de reforma do gás natural utiliza vapor de alta temperatura para transformar metano em hidrogênio e dióxido de carbono. Esta tecnologia tem sido utilizada em instalações industriais. O impacto ambiental, porém, é uma grande preocupação, já que este processo é um agente poluidor efetivo.

As células combustíveis representam uma rota de conversão energética que pode se aliar às fontes renováveis de energia e, assim, atender aos requisitos técnicos e econômicos que são necessários para o desenvolvimento energético sustentável (GOMES, 2011).

No Brasil, o programa brasileiro de hidrogênio e sistemas de células combustíveis tem como meta promover ações integradas e cooperadas, para que haja um maior desenvolvimento desta tecnologia. Habilitando o país a se tornar um produtor internacionalmente competitivo nesta área. Pretende-se ainda apoiar o estabelecimento de indústria nacional para produção e fornecimento de sistemas energéticos com célula combustível.

A partir da busca de uma melhor qualidade de vida, surge a necessidade de encontrar um novo vetor energético que não afete negativamente o meio ambiente ou prejudique as relações geopolíticas. O hidrogênio aparece no cenário socioeconômico como uma fonte de energia eficiente capaz de substituir os combustíveis fósseis. Esse componente químico é um vetor energético com teor zero de carbono. Assim como a eletricidade, o hidrogênio pode ser produzido a partir de todas as fontes de energia, como a biomassa, eólica, solar e combustíveis.
O hidrogênio pode ser caracterizado como um vetor energético limpo, versátil que permite muitos usos, incluindo iluminação, refrigeração, comunicação, processamento de informação e transporte. Segundo Silva et. al., (2018), a elevada eficiência de conversão das células combustíveis torna este elemento químico bastante promissor em comparação com alternativas de geração elétrica baseada em combustíveis fósseis, pois este processo não é só livre de poluentes e gases de efeito estufa, mas também utiliza consideravelmente menos energia primária para produção do mesmo.

É a energia solar, absorvida na fotossíntese, que dá vida às plantas utilizadas como fonte de energia de biomassa. Até mesmo o petróleo, que vem de restos de vegetação e animais pré-históricos, também é derivado do sol, pois este deu a energia necessária ao aparecimento da vida na terra em eras passadas. Podemos, através desse ponto de vista, considerar que todas as formas de energia são renováveis, infelizmente não em escala humana. As formas de energia renovável citadas acima são as que se renovam a cada dia, permitindo um desenvolvimento sustentável da vida e sociedade humana.

Painéis solares fotovoltaicos são dispositivos utilizados para converter a energia da luz do Sol em energia elétrica. Os painéis solares fotovoltaicos são compostos por células solares, assim designadas já que captam, em geral, a luz do Sol. Estas células são, por vezes, e com maior propriedade, chamadas de células fotovoltaicas, ou seja, criam uma diferença de potencial elétrico por ação da luz (FIGUEIREDO et al.,2018).

As células solares contam com o efeito fotovoltaico para absorver a energia do sol e fazem a corrente elétrica fluir entre duas camadas com cargas opostas. As células fotovoltaicas (ou células de energia solar) são feitas a partir de materiais semicondutores (normalmente o silício). Quando a célula é exposta à luz, parte dos elétrons do material iluminado absorve fótons (partículas de energia presentes na luz solar).

Os elétrons livres são transportados pelo semicondutor até serem puxados por um campo elétrico. Este campo elétrico é formado na área de junção dos materiais, por uma diferença de potencial elétrico existente entre esses materiais semicondutores. Os elétrons livres são levados para fora das células de energia solar e ficam disponíveis para serem usados na forma de energia elétrica. A Figura 1 exemplifica uma placa fotovoltaica. 


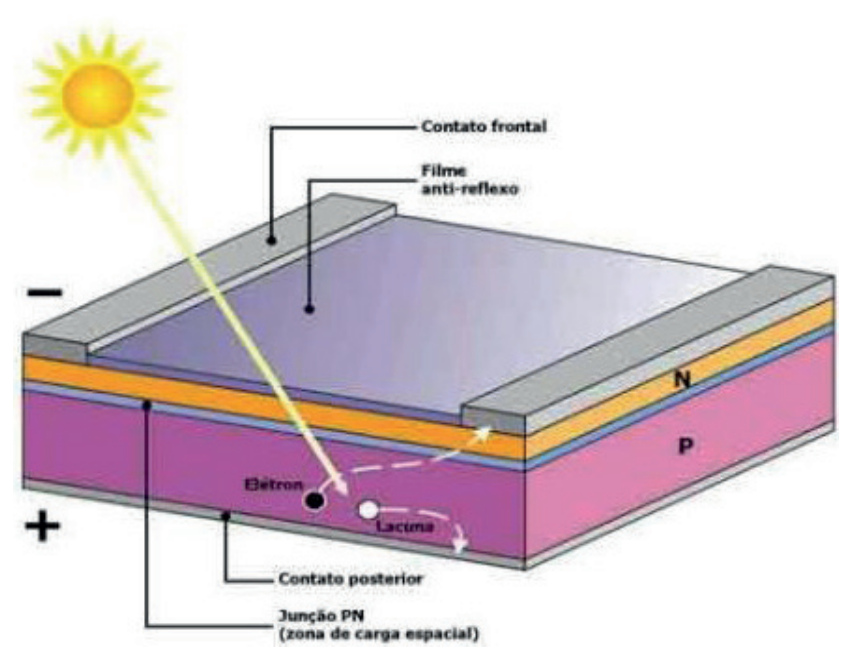

Figura 01 - Modelo de uma placa fotovoltaica Fonte: BRAGA,(2015).

O interesse neste sistema reside na eficiência do mesmo gerar energia utilizando uma fonte renovável como combustível. Diante desta nova perspectiva exposta, o presente trabalho tem como objetivo evidenciar o princípio de funcionamento de um reator eletrolítico, painel solar e uma célula combustível.

\section{METODOLOGIA}

A metodologia utilizada para os equipamentos e sistemas montados segundo Damasceno (2017) e Pinto (2014), foram os seguintes:

- Reator eletrolítico (Hy-PEM XP 024);

- Sistema de compressão (Hy-COMP XT - HP version);

- Célula combustível (FCS - c3000).

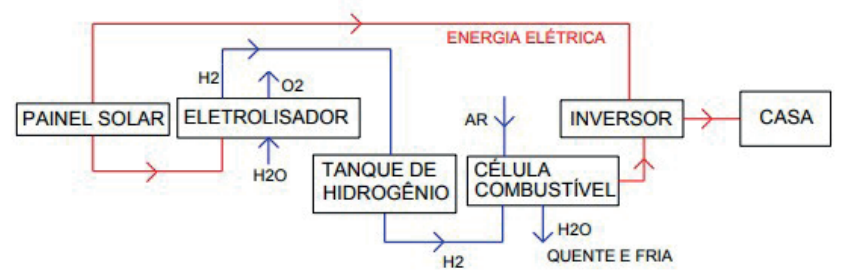

Figura 02 - Esquematização do sistema composto por uma célula de combustível, eletrolisador e painel solar

Fonte: Autores.

Para complementar o estudo desenvolvido por Damasceno (2017), acrescenta-se a pesquisa desenvolvida por Pinto (2014). Adicionam-se ao sistema painéis fotovoltaicos, um controlador de carga, um inversor e cilindros de armazenamento de hidrogênio. Logo, forma um sistema integrado como mostra a Figura 3:

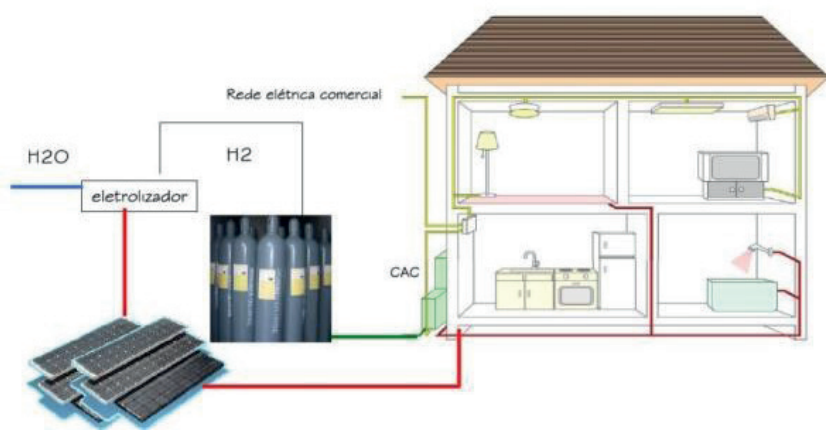

Figura 03 - Esquematização do sistema composto por uma célula de combustível, eletrolisador e painel solar Fonte: Silva, 2018

Para gerar energia o sistema funciona desde que, a luz solar inicie o processo de produção e estocagem de hidrogênio. Durante o dia o sistema pode obter energia elétrica dos painéis solares e da célula, e a noite ou em dias nublados, o sistema ativa a célula combustível.

O excedente de energia solar é utilizado para produzir hidrogênio e oxigênio através da eletrólise da água. $\mathrm{O}$ hidrogênio e o oxigênio podem ser armazenados em tanques onde estão prontos para serem utilizados na célula quando se necessita de energia elétrica.

A energia solar é utilizada para fazer a eletrólise da água através de um eletrolisador obtendo como resultado hidrogênio e oxigênio em estado gasoso. Esses gases são estocados e recombinados por intermédio de reações eletroquímicas dentro da célula combustível tendo como produto, água pura e energia elétrica.

O sistema ainda pode ser interconectado à rede de serviço público de abastecimento de energia, e quando houver hidrogênio sobrando e os dispositivos da casa estiverem em repouso a eletricidade adicional poderá ser injetada na rede de energia elétrica.

\section{RESULTADOS E DISCUSSÃO}

Segundo Damasceno (2017), os experimentos realizados para levantar as curvas de polarização foram utilizados primeiramente para verificar a geração de energia elétrica utilizando hidrogênio como combustível. Constatou-se que o funcionamento diário da célula fez com que a mesma passasse por um processo de "amaciamento" conseguindo alcançar a tensão máxima contida nas especificações do equipamento, 68,2V.

O resultado experimental mostrou que até o último funcionamento, a célula combustível foi capaz de fornecer uma potência de aproximadamente 1087W (25 A e 43,5V), um pouco mais de $36,6 \%$ da sua capacidade máxima. 
Para uma melhor compreensão dos resultados, Damasceno(2017) mostra uma curva relacionando o hidrogênio consumido em função da potência elétrica verificada, conforme a Figura 4.

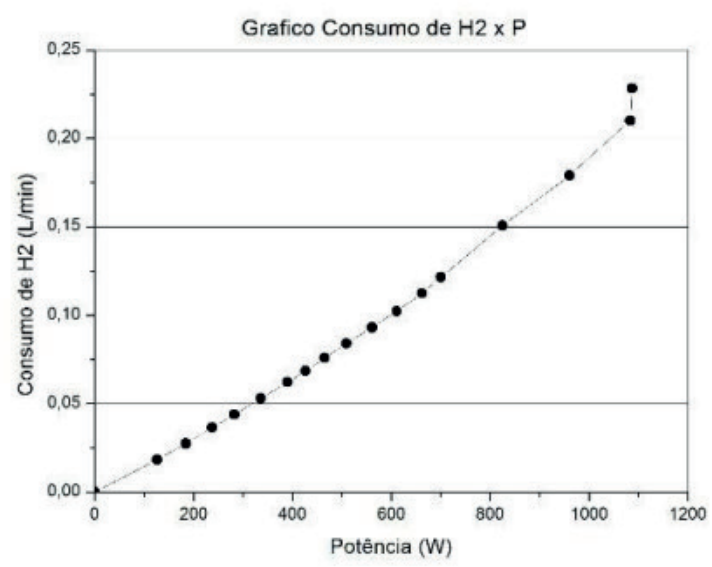

Figura 04 - Funcionamento da célula de combustível: consumo de H2 pela potência Fonte: DAMASCENO, (2017).

Conforme Braga (2015), um eletrolisador baseado na tecnologia PEM apresenta diversas vantagens sobre o convencional eletrolisador alcalino, tais como uma maior eficiência energética. A eficiência de um eletrolisador PEM cessitam de componentes mais especiais, incluindo uma membrana polimérica de alto custo e eletrodos porosos, além de coletores de corrente.

Foi feita a relação entre os custos entre produção de hidrogênio e o custo da energia solar, conforme a Figura 05 apresentada a seguir.

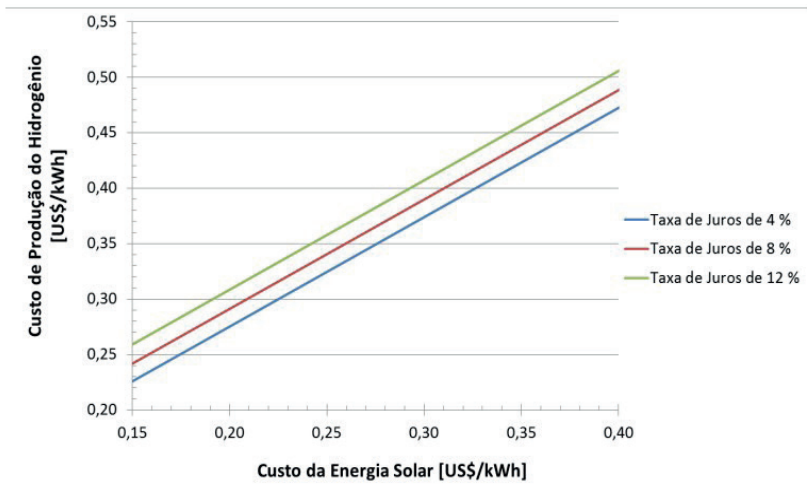

Figura 05 - Custos de $\mathrm{H} 2 \mathrm{x}$ custos de energia solar Fonte: BRAGA (2015)

Ainda, segundo Braga (2015), pela análise do gráfico, verifica-se que para a faixa considerada dos custos da eletricidade gerada a partir de PVs de 0,15 até 0,40 US\$/kWh são encontrados custos de produção de hidrogênio entre 0,23

e 0,51 US\$/kWh. Quanto à análise econômica, a produção do hidrogênio a partir da energia solar de painéis fotovoltaicos não se mostrou como sendo uma alternativa atrativa, apresentando custos significativamente superiores se comparados aos obtidos pelas fontes eólica e hidrelétrica. Tal fato explica-se devido ao elevado custo de geração de energia elétrica atualmente obtida por essa fonte.

Os valores dos custos de produção de hidrogênio encontrados para fontes renováveis são significativamente maiores que os de fontes fósseis. Desta forma, vale ressaltar a importância de políticas de incentivo às fontes renováveis, com auxílios governamentais à produção de hidrogênio por fontes não fósseis, podendo tornar mais atrativa aos investidores essas alternativas.

A partir dos dados apresentados na Figura 6, nota-se que o melhor rendimento global para a geração de hidrogênio é a oxidação parcial de hidrocarbonetos e eletrólise da água com acionamento do eletrolisador por usinas hidrelétricas.

\begin{tabular}{|c|c|c|c|}
\hline \multicolumn{4}{|l|}{ Desempenho - Rendimento } \\
\hline Aspectos Economicos & $\mathrm{RD}$ & Harmonização & eVetor \\
\hline Reforma à Vapor (RV) & 80,0 & 0,25 & 0,25 \\
\hline Oxidação Parcial (OP) & 75,0 & 0,24 & 0,24 \\
\hline Gaseificação do Carvão (GC) & 55,0 & 0,17 & 0,17 \\
\hline Eletrólise - Solar (EL) & 14,0 & 0,04 & 0,04 \\
\hline Eletrólise - Eólica (EE) & 31,5 & 0,10 & 0,10 \\
\hline Eletrólise - Hidrelétrica (EH) & 63,0 & 0,20 & 0,20 \\
\hline
\end{tabular}

Figura $06-v$

Fonte: BRAGA, (2015).

A partir dos resultados apresentados, formula-se os seguintes lugares para a instalação do sistema já supracitado:

- Hospitais;

- Ilhas de pequeno porte;

- Condomínios que procuram sustentabilidade;

- Semiárido da Paraíba;

- Entre outros locais que possuam alta insolação;

Para hospitais, esse sistema é favorável. Em caso de ausência de energia elétrica da rede, o sistema com placa solar, eletrolisador e célula substitui geradores convencionais e baterias. Além de necessitar de pouca quantidade de água, visto que uma vez abastecido o reator pode funcionar por semanas, os aparelhos praticamente não produzem ruídos, aspectos importantes para um ambiente hospitalar. Não só isso, provem de fontes renováveis em oposição aos combustíveis fósseis utilizados em geradores. 
Para uma ilha de pequeno porte, tal proposta torna-se aceitável. Desde que esteja localizada próxima à linha do Equador, isso pode ser instalado. Devido à disponibilidade de luz do sol e água (necessários para a placa e reator) e o pequeno espaço (notando-se que o sistema ocupa um espaço mínimo) a geração de energia através da proposição deste artigo também é aplicável.

Por fim, em condomínios que desejam energia limpa, o sistema também pode ser instalado. Para diminuir custos com iluminação, cerca elétrica e portões automáticos, além de prevenção de um apagão, a geração de energia elétrica por meio de placa solar, eletrolisador e célula se aplica eficientemente.

Na figura 7, pode-se observar locais no Brasil nos quais há maior incidência de raios solares e consequentemente ideais para o sistema de geração de energia renovável.

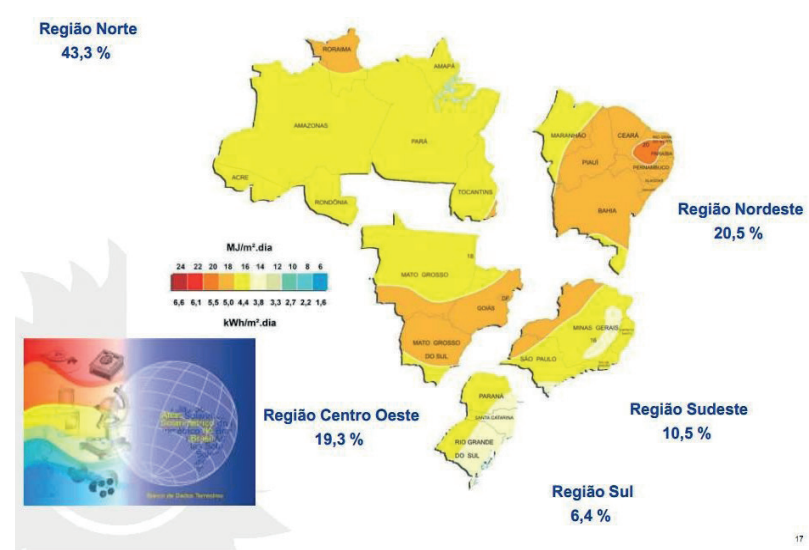

Figura 07 - Radiação solar global diária - média anual típica ( $\left.\mathrm{MJ} / \mathrm{m}^{2} \mathrm{dia}\right)$ Fonte: Solar,2017

O sistema de produção de energia elétrica a partir do hidrogênio pode ser instalada no Nordeste, mais especificamente no estado da Paraíba.

Segundo estudos da Empresa de Pesquisa Energética (EPE), a geração solar fotovoltaica centralizada, cujos projetos são oriundos principalmente de leilões promovidos pelo Governo Federal, crescerá, em média, expressivos 84,6\%a.a. de 2016 até 2026, alcançando 9,7 GW, montante que corresponderá a 4,7\% da capacidade instalada de geração do Brasil . O Nordeste será a região mais contemplada nos investimentos previstos, em função de sua elevada competitividade nessa atividade.

O Operador Nacional do Sistema (ONS)(2018) constatou que a geração de energia eólica e solar na região Nordeste é promissora. A energia solar registrou recorde de geração instantânea ao atingir um pico de 675 megawatts (MW), o fator de capacidade instalada chegou a $86 \%$. Na figura 8 são apresentados os dados da incidência de raios solares na região Nordeste.

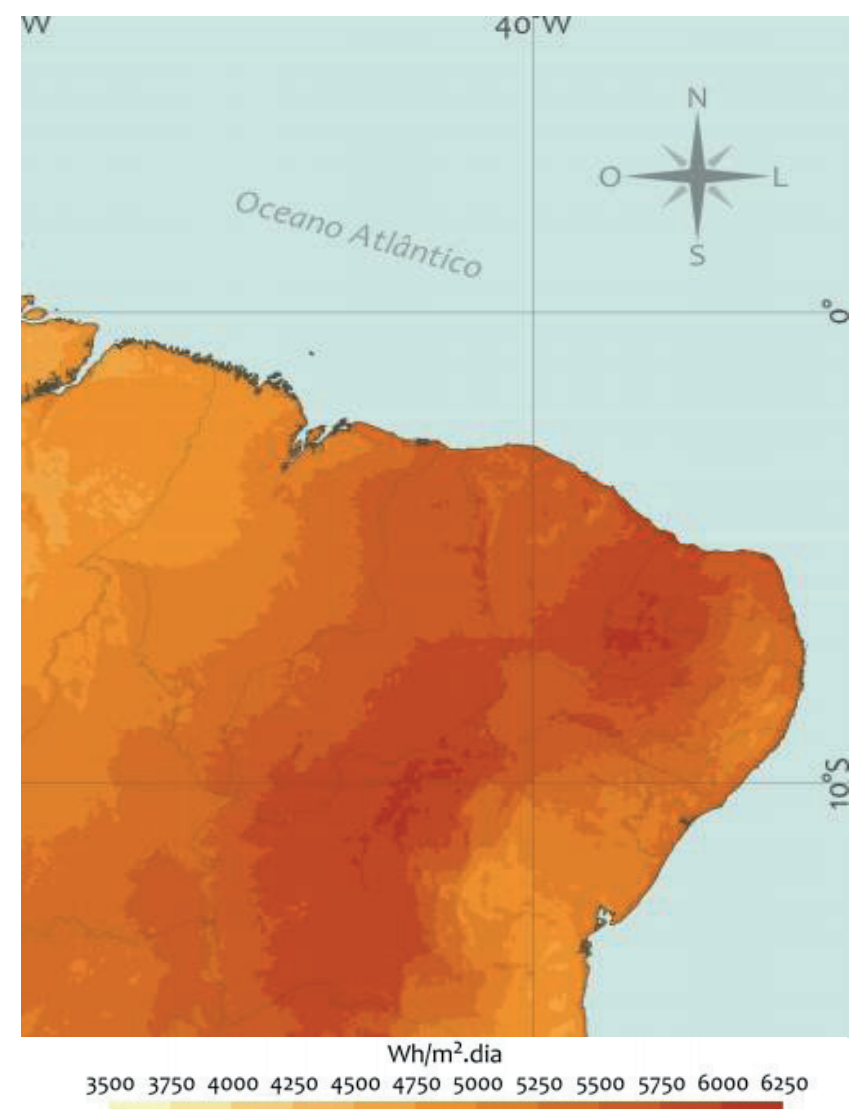

Figura 08 - Incidência de raios solares na região Nordeste Fonte: Atlas Brasileiro de Energia Solar (2017)

Uma região que apresenta potencialidade de energia renovável é o Sertão do Estado da Paraíba, na qual apresenta uma alta incidência de luz solar, especificamente nas cidades (Coremas, Catolé do Rocha e Sousa), despertado o interesse de empresas para a instalação de usinas que utilizam o sol como fonte de geração de energia. Cidades como Sousa e Patos têm uma radiação média anual de $20 \mathrm{MJ} / \mathrm{m}^{2}$. Em um mês como dezembro, por exemplo, a Paraíba tem uma incidência de $24 \mathrm{MJ} / \mathrm{m}^{2}$ a 26 $\mathrm{MJ} / \mathrm{m}^{2}$ (DUQUE,2018).

\section{CONSIDERAÇÕES FINAIS}

A energia solar pode contribuir de maneira significativa para geração de energia elétrica. Atualmente, a produção de energia solar não está consolidada no Brasil, quando comparada à hidroeletricidade. Para alguns casos, como comunidades afastadas, por exemplo, ou onde não existem alternativas é favorável a utilização de geração de energia solar. Durante a pesquisa foi possível verificar que a radiação do sol pode contribuir de diversas maneiras com a economia de energia, inclusive na produção de hidrogênio a partir de um reator eletroquímico alimentado por uma placa fotovoltaica. Além disso, a utilização do hidrogênio 
como fonte sustentável de energia mostra-se um caminho promissor. No sistema apresentado para gerar hidrogênio, é através da separação da água, utilizando energia elétrica para dividi-la em hidrogênio e oxigênio. A eletrólise praticamente, não apresenta nenhuma poluição ou subprodutos tóxicos, se a corrente elétrica é gerada utilizando energias renováveis, tais como energia solar ou eólica. Diante do exposto e da dificuldade existente na atualidade, em produzir energia suficiente para a demanda, é necessário a escolha de energias alternativas e limpas, neste caso, foi proposto a geração de energia elétrica a partir de um sistema composto por um eletrolisador, painel solar e uma célula de combustível. Os Estados da Paraíba e do Rio Grande do Norte são favoráveis para este tipo de geração, isso é verificado através de atlas Solarimétricos que indicam essa região, como propícia à produção de energia solar.

\section{REFERÊNCIAS}

ANEEL. Agência Nacional de Energia Elétrica. Altas de energia elétrica do Brasil.

Brasília, ANEEL: 2005. 243p. 2005.

BRAGA, G. G. A. Aspectos técnicos, econômicos e de sustentabilidade da produção de hidrogênio renovável. 2015. 80 p. Dissertação (Mestrado em Engenharia de Guaratinguetá, Universidade Estadual Paulista, Guaratinguetá, 2015.

DAMASCENO, A. S. produção de energia elétrica utilizando hidrogênio como combustível. 2017. 97p. Trabalho de Conclusão de Curso. Universidade Federal de Campina Grande. Campina Grande, PB.

FIGUEIREDO, Hugo Fernando Magalhães; PODOLAK, Lucas; SCHULTZ, Lilian Rosana Kremer. projeto e desenvolvimento de um sistema fotovoltaico autônomo voltado a área rural. Revista Técnico-Científica, n. 15, 2018.

GOMES, W. Z. Elaboração de Protocolo de Testes para Células a Combustível Portáteis. Dissertação de Mestrado, 2011.

KNOB, D. Geração de Hidrogênio por Eletrólise da Água Utilizando Energia Solar Fotovoltaica. Dissertação de Mestrado, 2013.

KNABBEN, Marcel Augusto et al. Sistema de Armazenamento e Gerenciamento de Energia Solar Fotovoltaica Aplicado em um Protótipo Funcional Photovoltaic Solar Energy Storage and Management System Applied to a Functional Prototype. Braz. J. Technol, v. 1, n. 2, p. 334-343, 2018.

PEREIRA, Enio et al. Atlas Brasileiro de Energia Solar. $2^{\circ}$.

ed. São José dos Campos:[s.n.],2017. 89

p.

Disponível em:

$<$ http://ftp.cptec.inpe.br/labren/publ/livros/Atlas_ Brasileiro_Energia_Solar_2a_Edicao.pdf $>$. Acesso em: 06 dez. 2018.

SOLAR, Energia. Energia Solar. Recopilado de: https:// autosolar. es/bateriasagm/bateria-agm-12v-220ah-victron-energy. El, v. 20, 2017.

SILVA, Julierme Siriano; FERREIRA, Alan Henrique Rios; JÚNIOR, Joel Carlos Zukowski. estudo de viabilidade econômica de microgeração de energia solar integrada à rede na uft campus gurupi-to. revista cereus, v. 9, n. 1, p. 88-105, 2017.

ZENG, K.; ZHANG, D. Recent progress in alkaline water electrolysis for hydrogen production and applications. Progress in Energy and Combustion Science, v. 36, n. 3, p. 307 326, 2010. Elsevier Ltd. Disponível em: Acesso em: 20/07/2019 


\section{AUTORES}

ORCID: https://orcid.org/0000-0002-7920-4107

VANESSA ROSALES BEZERRA, M.Sc. | Universidade Estadual da Paraíba | PPGCTA - Doutoranda Engenharia Ambiental| Campina Grande, PB. Brasil | Correspondência para: Rua Juvêncio Arruda, S/N - CEP: 58429-600 - Campus Universitário, Bodocongó - Campina Grande - PB | E-mail: rosalesuepb@gmail.com

ORCID: https://orcid.org/0000-0002-1301-6066

CARLOS ANTÔNIO PEREIRA DE LIMA, DR. | Universidade Estadual Da Paraíba | PPGCTA - Programa de Pós Graduação em Ciência e Tecnologia Ambiental | Campina Grande, PB. Brasil | Correspondência para: Rua Juvêncio Arruda, S/N - CEP: 58429-600 - Campus Universitário, Bodocongó Campina Grande - PB | E-mail: caplima@uepb.edu.br

ORCID: https://orcid.org/0000-0002-1462-5963

LUIS REYES ROSALES MONTERO, DR. | Universidade Federal de Campina Grande |DEE-Departamento de Engenharia Elétrica | Campina Grande, PB. Brasil | Correspondência para: Rua Aprígio Veloso, 882 - Bairro Universitário - Campina Grande PB - CEP 58429-900 |E-mail: professorluisreyes@hotmail.com

ORCID: https://orcid.org/ 0000.0001.5861.7407

VALDERI DUARTE LEITE, Dr. | Universidade Estadual da Paraíba | PPGCTA - Programa de Pós Graduação em Ciências e Tecnologia Ambiental | Campina Grande, PB. Brasil | Correspondência para: Rua Juvêncio Arruda, S/N - CEP: 58429-600 - Campus Universitário, Bodocongó - Campina Grande - PB | E-mail: mangabeiraleite@hotmail.com

ORCID: https://orcid.org/0000-0001-9250-1432

KEILA MACHADO DE MEDEIROS, Dra. | Universidade Federal do Recôncavo da Bahia-UFRB | Centro de Ciência e Tecnologia em Energia e Sustentabilidade-CETENS | Avenida Centenário, 697, Bairro SIM ,CEP:44085-132, Feira de Santana-BA | E-mail: keilamedeiros@ufrb.edu.br

\section{COMO CITAR ESTE ARTIGO}

BEZERRA, Vanessa Rosales; LIMA, Carlos Antônio Pereira de; MONTERO, Luis Reyes Rosales; LEITE, Valderi Duarte; MEDEIROS, Keila Machado de. Implementação de Sistemas Autônomos de Geração de Energia para a Região do Semiárido Paraibano. MIX Sustentável, [S.I.], v. 5, n. 4, p. 89-95, nov. 2019. ISSN 24473073. Disponível em:<http://www.nexos.ufsc.br/index.php/ mixsustentavel>. Acesso em: dia mês. ano. doi:https:// doi.org/10.29183/2447-3073.MIX2019.v5.n4.89-95.
DATA DE ENVIO: 01/09/2019

DATA DE ACEITE: 04/10/2019 
